viduell hergestellten Testallergenen arbeiten, die Testroutine in den niedergelassenen Praxen wird aber verarmen. Denn nicht jeder Niedergelassene ist bereit, mit „illegalen“ Substanzen aus dem Ausland oder aufwendig selbst ge-

\title{
Berufsallergen Robinie?
}

$\mathrm{N}$

eue Arbeitsprozesse können zu bislang nicht vermuteten Sensibilisierungen führen. Den Beleg dafür trat Priv.Doz. Dr. Monika Raulf-Heimsoth, Bochum, mit dem Fall eines 52-jährigen Schlossers in einer Spielzeugfabrik an. Der Mann litt beim Arbeiten mit Robinienholz (Robinia pseudacacia) zunehmend unter asthmatischen Beschwerden sowie Rhinokonjunktivitis. In der Spirometrie zeigte sich eine milde bronchiale Hyperreagibilität. Der Patient reagierte im Pricktest auf eine Vielzahl von Hölzern negativ, nur bei Robinie war eine positive Reaktion nachweisbar, das spezifische IgE lag bei $0,9 \mathrm{kU} / \mathrm{l}$. In der bronchialen Provokation ergab sich eine klare Absenkung des FEV , bei Provokation gegenüber Robinienextrakt. Der IgE-Immunoblot wies zwei Banden bei 45 und $28 \mathrm{kDa}$ auf, die offensichtlich als Allergene erkannt wurden. Damit stand Robinienholz als Auslöser fest.

Robinienholz sollte in die Liste der Berufsallergene aufgenommen werden, empfahl Raulf-Heimsoth. Der Baum stammt ursprünglich aus Nordamerika, besitzt ein sehr festes und dauerhaftes Holz und wird häufig im Außenbereich eingesetzt. Da es als Alternative zu Tropenhölzern gilt, ist mit einer Zunahme der Sensibilisierungen zu rechnen.

Raulf-Heimsoth M. Neue berufliche Allergene

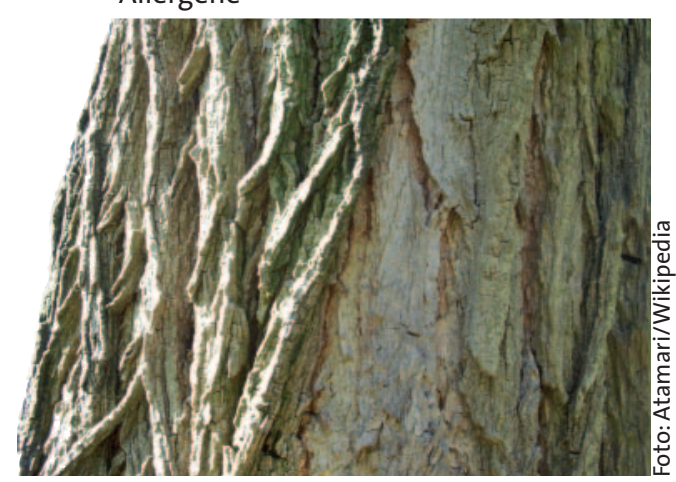

bastelten Allergentestreihen die Lücke zu füllen.

Derzeit laufen Gespräche mit den Entscheidungsträgern, um die Regelung zu ändern. Sollte das nicht zum Erfolg führen, werden die wissenschaftlichen
Beiträge auf den nächsten Allergiekongressen sich dann wohl eher mit dem Thema „Noch verfügbare Kontaktallergene" beschäftigen müssen.

$b k$

Becker D. Neue Kontaktallergene 